\title{
Reconstituição das Esculturas Conhecidas como " Anjos da Praça” por Meio das Técnicas de Fotogrametria e Prototipagem em Escala Reduzida
}

\section{Sculptures' Reconstitution Known as "Square Angels" through the Techniques of Photogrammetry and Prototyping in Reduced Scale}

\author{
Cristiano Corrêa Ferreira \\ Doutor em Engenharia de Minas, Metalúrgia e de Materiais pela Universidade Federal do Rio Grande do Sul (UFRGS) - \\ cristiano.ferreira@unipampa.edu.br - orcid.org/0000-0002-7676-9233 \\ Roberto Pozzer \\ Graduando em Engenharia de Produção pela Universidade Federal do Pampa (UNIPAMPA)- \\ rbrtbetopozzer@gmail.com - orcid.org/0000-0002-1541-8667
}

\section{Resumo}

Este trabalho tem por objetivo descrever duas técnicas utilizadas para reconstituir duas esculturas utilizadas em dois chafarizes de uma praça da cidade de Bagé-RS. Essa iniciativa, além de inovadora para o contexto local, visa também alertar a comunidade da cidade e região sobre a importância de proteger essas e outras esculturas antigas. Nos dias atuais, as ferramentas de modelagem tridimensional são extremamente úteis porque facilitam a reprodução de objetos de significativa complexidade que, dificilmente, conseguiríamos representar em softwares CAD de desenho convencionais. Sendo assim, estruturou-se uma metodologia para modelar em 3D (fotogrametria) e imprimir (prototipagem rápida), na escala reduzida e com material polimérico, as esculturas. Ao final dessa ação, detectou-se que será possível modelar mais estatuetas e bustos de outras obras que estão nas praças e locais públicos da cidade porque, da forma como estão hoje, esses elementos correm o risco de destruição em função dos períodos de intempéries, degradação de vândalos e depredadores, entre outros.

Palavras-chave: Arte e tecnologia; Monumentos - Conservação e restauração; Escultura Pública; Impressão tridimensional; Arte municipal.

\begin{abstract}
The paper aims to describe two techniques employed on reconstituted sculptures used on two fountains at a square located on the city of Bagé, in the state of Rio Grande do Sul, Brazil. This initiative, is innovative for the local context, also intends to alert the community of the city and region about the importance of protecting these and other ancient sculptures. Nowadays the three-dimensional modeling tools are extremely convenient considering that they facilitate the reproduction of significant-complexed objects, which we could hardly represent on conventional CAD drawing softwares. For this purpose, it has been structured a methodology intending to model in 3D (photogrammetry) and to print (with rapid prototyping) the sculptures, using a reduced scale and a polymeric material. At the end of this action, it was detected the possibility of modelling more statuettes and busts of other works that are on the squares and public places of the city. Because, as these elements are presented today, they face the risk of being destroyed due to periods of weather, degradation of vandals and predators, among others.
\end{abstract}

Keywords: Art and technology; Monuments - Conservation and restoration; Public sculpture; Threedimensional printing; Art, Municipal. 


\section{INTRODUÇÃO}

A reconstrução física de esculturas permite abrir possibilidade para novos estudos, trabalhos de reconstituição da história, reprodução de novos exemplares, bem como experiências das mais diversas. Em função disso, procurou-se representar duas estatuetas conhecidas como os anjos da praça, que provavelmente estejam lá desde 1908.

Segundo dados encontrados Blog Bagé, terra do Tempo e o Vento (2011a), a Praça Silveira Martins já teve vários nomes: Largo do Conde, Praça do Portão, (porque próximo à praça haveria um portão, que seria o de entrada da cidade), Praça do Mercado e Praça Voluntários da Pátria, em 1881, (pois era nela que os soldados do Brasil que foram para a Guerra do Paraguai se reuniam). A atual denominação de Praça Silveira Martins se deu em homenagem a Gaspar Silveira Martins e vigora desde o final de 1930. De acordo com informações disponíveis no Blog Bagé, terra do Tempo e o Vento (2011b), Gaspar Silveira Martins, nasceu em Aceguá-RS e foi advogado, deputado, ministro da fazenda, senador, um dos fundadores do Partido Federalista e, também, presidente da Província do Rio Grande do Sul em 1889.

Essa praça está situada bem no centro da cidade de Bagé-RS. Em 1908, foram construídos dois chafarizes que vieram do Rio de Janeiro e, conforme relatos de historiadores, os dois "anjinhos da praça" vieram nessa mesma época. Recentemente, em meados de 2019, as fontes que fazem parte da estrutura dos anjos foram revitalizadas. Em relação a dados históricos desses anjos, não se encontraram maiores detalhes a respeito de procedência e, até mesmo, de quem trouxe. Foram feitas pesquisas nos mais diversos locais da cidade como: nos jornais do museu Dom Diogo de Souza, consultas com os historiadores da cidade, no entanto nada de concreto foi encontrado.

Em função da falta de informações a respeito dessas duas esculturas, motivou-se a reproduzi-las em escala reduzida nesse trabalho e, para isso, foi necessário utilizar recursos tecnológicos, considerados inovadores para o contexto regional pois, segundo Dezen-Kempter et al. (2015), na última década, o uso de tecnologias de digitalização 3D para coletar remotamente informação espacial foi popularizado por gerar uma quantidade enorme de dados. Além disso, os autores destacam que a tecnologia de fotogrametria e escaneamento 3D são sistemas de aquisição tridimensional, automatizados e sem contato como o objeto analisado, que usam sensores fundamentados em ondas de luz para a medição, direta ou indireta, do produto. 
Padín Devesa; Buchón Moragues; Sánchez Jiméne (2015) ratifica os conceitos e informações dos autores anteriores e enfatiza que o uso das tecnologias em 3D está crescendo e, dessa forma, torna-se uma necessidade para todos os profissionais que estão relacionados com o patrimônio nas áreas de conservação, de restauro, de escultura e modelagem, de design e da criação de espaços virtuais. Mas, vale lembrar que é necessário ter algum conhecimento sobre as diferentes técnicas de aquisição e tratamentos de dados tridimensionais que permitem, hoje, transformar objetos reais em suas variantes digitais, mantendo seu rigor métrico. Essas diferentes metodologias foram aplicadas para obter réplicas leves de ornamentos em fachadas de edifícios.

Cóser (2010) destaca que o estado da arte tecnológico nos permite exercer funções complexas e o computador tornou-se uma peça-chave na vida moderna, aumentando a velocidade e eficiência de tarefas que, muitas vezes, seriam até mesmo impraticáveis sem esta ferramenta. No mesmo contexto, Veiga et al. (2013) apresentam um projeto que inclui a representação de elementos relativos ao patrimônio arquitetônico, os quais podem abarcar formas poliédricas, quadráticas ou livres. O exemplo apresentado no artigo inclui o processo de modelagem e fabricação digital, em escala reduzida, de um artefato que configura uma das sacadas de um edifício do entorno da Praça Coronel Pedro Osório, no centro de Pelotas-RS.

Há pouco, Tranjan; Ferreira; Lucas. (2019) desenvolveu um estudo onde fez, por meio de fotogrametria e prototipagem 3D, a reconstituição da escultura grega de Selênio com Dionísio.

Assim sendo, a hipótese dessa investigação caracteriza-se por responder à seguinte questão: a modelagem 3D por fotogrametria e prototipagem rápida por impressora 3D permitem a caracterização e reprodução de esculturas localizadas em ambientes públicos a céu aberto?

Diante disso, o objetivo desse trabalho foi o de reconstituir duas esculturas antigas que estão instaladas, desde meados de 1908, no chafariz de uma praça histórica da cidade de Bagé-RS.

Para atingir esse objetivo foram utilizadas a técnica de fotogrametria e a prototipagem rápida que se caracterizam por possuírem condições importantes para a viabilização do estudo, ou seja, a primeira por ter custo barato e a segunda por ser eficiente e inovadora para a nossa região.

\section{REVISÃO TEÓRICO CONCEITUAL}

De acordo com Castro (2019), escultura urbana significa monumentos instalados em espaços públicos e patrocinados pelo estado, que narram um fato ou adornam o ambiente. Esse 
tipo de esculturas comemorativas e educativas foi a corrente principal da prática da arte pública sendo que, no Brasil, este movimento teve início em 1862. Segundo a autora:

\begin{abstract}
Esses monumentos fazem parte da memória coletiva, celebra temas e personagens ligados às estruturas de poder e à própria história do Estado e do País. Localizadas, em geral, em praças públicas, as estátuas compõem a função do lugar como locais de convívio social, contemplação e lazer. Essas esculturas integram a categoria de monumentos intencionais e possuem elementos essenciais que cumprem uma função de rememoração. Porém, em razão da ausência ou ineficiência de políticas públicas de preservação ou valorização destes bens, os significados e o que eles representam podem passar despercebidos pela população, ou até mesmo terem sua intencionalidade confundida com a de outros monumentos, (CASTRO, 2019, p. 28).
\end{abstract}

Para Botelho (2013), à medida que os objetos são analisados em seu contexto histórico, eles revelam as estruturas de produção, de consumo, de renda e social. Para o autor, isso pode significar uma estratégia que permite contextualizar a história espacial, abarcar a dinâmica da sociedade, perceber a coexistência do passado e presente e compreender as transformações espaciais, como maneira de pensar e projetar o futuro. Além disso, o mesmo autor enfatiza que esses objetos representam também as heranças de formação espacial nas diferentes etapas de desenvolvimento da sociedade, assim como são marcas de um universo simbólico, dotado de sentimentos intrínsecos ao observador e produto da apropriação e transformação do mesmo pelo homem, um ciclo aberto do qual podemos extrair diferentes desdobramentos.

Recentemente, Moragi (2020) publicou um estudo sobre a praça Silveira Martins, onde faz uma análise detalhada sobre a sua funcionalidade ambiental, paisagística e social desse local para os moradores. Ainda nesse trabalho, o autor relata que as praças públicas se caracterizam como locais de significativo valor histórico, cultural e de interação social, representando, portanto, elementos fundamentais na configuração urbana e constituindo um dos mais importantes espaços públicos da história das cidades brasileiras.

Nos últimos anos, tem-se discutido muito sobre formas de se conservar os bens culturais materiais e, segundo Silva (2019), a deterioração de bens materiais pode ocorrer por um ou mais fatores como: climáticos, ação do tempo, fatores biológicos, por fatores antropogênicos que derivam da ação humana, por meio da poluição atmosférica, intervenções inadequadas, vandalismo e manuseio e/ou exposição inapropriadas. 
Silva também reforça, em seu estudo, que a relação direta do patrimônio com a história e a memória possibilita que a identidade e as tradições de uma sociedade sejam preservadas para outras gerações e destaca que esses objetos, em geral, carregam simbolismos que ultrapassam a materialidade física e vão ao encontro do sagrado, possuindo, assim, um significado particular para a sociedade.

Bonora et al. (2021) desenvolveram, recentemente, um projeto com o propósito de reproduzir estátuas de um batistério pois havia uma enorme preocupação dos gestores com a preservação por questões de segurança do local. A reprodução das cópias ocorreu com a utilização de impressoras do tipo FDM.

Ruth (2020) considera que somos sujeitos históricos, síntese de múltiplas determinações, motivo pelo qual as sociedades não são estáticas, é que se recorre aos símbolos, aos monumentos, à preservação das memórias dos fatos e personagens que marcaram, de alguma forma, a história de determinadas comunidades. Diante disso, as comunidades acomodam nos espaços públicos abertos para construírem monumentos e símbolos de poder, principalmente, político, econômico, social ou religioso.

Os anjos encontrados na praça têm sua essência associada à esfera religiosa e social que emergiu durante o período de apogeu econômico da cidade. Logo, os anjos despertam o interesse e a contemplação até os dias atuais. Por esse caminho, esses elementos revelam a relação do espaço público com os monumentos que estimulam as práticas religiosas e sociais de uma memória coletiva.

Para Selden; Dockall; Shafer (2018) e Matos (2020), as tecnologias juntamente com as ferramentas digitais estimulam o desenvolvimento e implementação de muitas técnicas, novos softwares e, também, se encontram em evolução em todas as áreas ao proporcionarem, por exemplo, uma nova forma de documentação gráfica do patrimônio onde se promove a inovação na forma como o profissional planeja e executa uma intervenção em uma peça de arte.

Vale ressaltar que as tecnologias estão sendo muito utilizadas para a conservação, restauração e reprodução de bens e monumentos. O trabalho de Fernandez Córdoba (2012), por exemplo, propôs o uso da fotogrametria a curta distância e a sua utilização como ferramenta de apoio a veículos aéreos não tripulados (VANT's), com câmeras digitais de pequeno formato como alternativa para levantamentos arquitetônicos que viabilizam o estudo da forma e das dimensões 
de um objeto por meio de fotografias. Para o autor, essa técnica converte-se em uma prática versátil para solucionar alguns problemas que são encontrados na etapa de levantamento.

Roussel et al. (2019) acrescenta que a fotogrametria permitiu estabelecer metodologias multidisciplinares, conduzindo geralmente a métodos menos invasivos para o desenvolvimento de protocolos de restaurações.

De Bonfada; Kauffmann; Silva (2020) enfatizam que o uso das novas tecnologias digitais viabiliza estratégias para a documentação e preservação do patrimônio cultural, e a utilização da digitalização 3D permite o registro digital de obras do patrimônio, ao passo que possibilitam o desenvolvimento de análises e estudos. Lu, Chenling (2020) ratifica as informações passadas por Freitas et al anteriormente e para ambos os autores, as digitalizações podem ainda ser utilizadas para a produção de réplicas fidedignas de obras danificadas ou furtadas.

Já Sá et al. (2019), por sua vez, acrescenta que a tecnologia é considerada como um meio que serve para conectar comunidades e sua herança. No mesmo trabalho, o autor destaca o papel da digitalização 3D nos dias atuais pois, em geral, as réplicas digitais em 3D podem ser manipuladas pelo usuário através de softwares de modelagem e animação 3D.

Donadio et al. (2018), acrescenta que, no campo da modelagem 3D, é possível modelar com precisão bens patrimoniais significativos que se encontram em risco pois muitos museus, nos últimos tempos, se valem das obras digitalizadas para realizarem exposições mais interativas e imersivas por meio da realidade virtual.

Em função do exposto acima, este trabalho busca digitalizar por meio da fotogrametria e imprimir por meio da prototipagem, duas esculturas que estão, desde meados de 1908, em uma praça pública e que fazem parte da memória de várias gerações. No entanto, no atual contexto em que vivemos, faz-se necessário o uso de ações mais concretas que visam à catalogação gráfica dessas imagens, por exemplo, este trabalho de cunho acadêmico que tem o propósito de otimizar o processo de reconstituição. Por isso, foi necessário estruturar um cronograma para o desenvolvimento metodológico das etapas de modelagem e prototipagem que serão detalhadas a seguir. 


\section{DESENVOLVIMENTO METODOLÓGICO}

Esta pesquisa se caracteriza por ser um estudo de caso que se fundamentou nas seguintes etapas: primeiramente, foram feitas inúmeras fotos in loco em diversos ângulos e posições das duas estatuetas até completar todo o entorno do objeto; a segunda etapa representou o momento em que essas imagens foram levadas para o software de fotogrametria denominado RECAP da Autodesk versão Educacional, que modelou as estatuetas em 3D; a terceira etapa significou o momento em que o modelo 3D representado na etapa anterior foi salvo em arquivo do tipo "STL" e, após, foi enviado para o software CAM de prototipagem REPETIER HOST, que fez a leitura e a programação em software de fatiamento CURA ENGINE da prototipagem das peças; a quarta etapa representa o momento em que as peças foram impressas em uma escala inferior ao tamanho original em uma impressora 3D, modelo Sethi 3D AIP. A seguir serão detalhadas essas etapas.

\subsection{FOTOGRAMETRIA}

Segundo Giné (2018) e Tommaselli et al. (1999), o termo fotogrametria deriva das palavras gregas fotos, que significa luz, gramma, que quer dizer algo desenhado ou escrito e metron, que consiste em "medir". Portanto, Fotogrametria, de acordo com suas origens, significaria "medir graficamente usando luz". A definição de Fotogrametria até a década de 60 era: "ciência e arte de obter medidas confiáveis por meio de fotografias" (American Society of Photogrammetry). Com o advento de novos tipos de sensores, uma definição mais abrangente de Fotogrametria foi proposta também pela American Society of Photogrammetry em 1979, como sendo Fotogrametria a arte, ciência e tecnologia de obtenção de informação confiável sobre objetos físicos e o meio ambiente através de processos de gravação, medição e interpretação de imagens fotográficas e padrões de energia eletromagnética radiante e outras fontes.

Ainda de acordo com Tommaselli et al. (1999), a digitalização por fotogrametria é realizada a partir de uma sequência de imagens fotográficas, obtidas de diferentes pontos de vista onde, durante o processamento, o software realiza o alinhamento tridimensional das imagens capturadas com base na detecção de sobreposições e pontos equivalentes, determinando, dessa maneira, a posição e orientação da câmera relativa ao objeto fotografado. A partir dessa orientação, é realizada a triangulação de diversos pontos detectados, restituindo assim a geometria tridimensional do objeto, em forma de nuvem de pontos ou malha tridimensional. 
Para De la Torre-Cantero et al. (2015) as tecnologias utilizando o software RECAP permitem reproduzir réplicas de uma maneira muito econômica, possui fácil manuseio e é bastante intuitivo.

Vale destacar que existem equipamentos e softwares com mais recursos e melhor precisão; no entanto, são de custo alto e geralmente requerem conhecimento específico para o manuseio.

Nesse contexto, a primeira etapa dessa investigação representou o momento em que as imagens dos anjos foram fotografadas através de uma máquina fotográfica digital modelo Coolpix P510, da Universidade Federal do Pampa (UNIPAMPA). A Figura 1 (a, b, c) e a Figura 1 (d, e, f) ilustram algumas das imagens das Estatuetas e vale lembrar que, para o desenvolvimento da análise, esses elementos foram denominados de Anjo 1 e Anjo 2, respectivamente. Ao todo foram tiradas aproximadamente 43 fotos de maneira sucessiva ao redor de cada imagem, no sentido horário, com o intuito de ilustrar o máximo de detalhes dos modelos.

Figura 1 - Fotos do Anjos 1 (a,b,c) e do Anjo 2 (d,e,f).

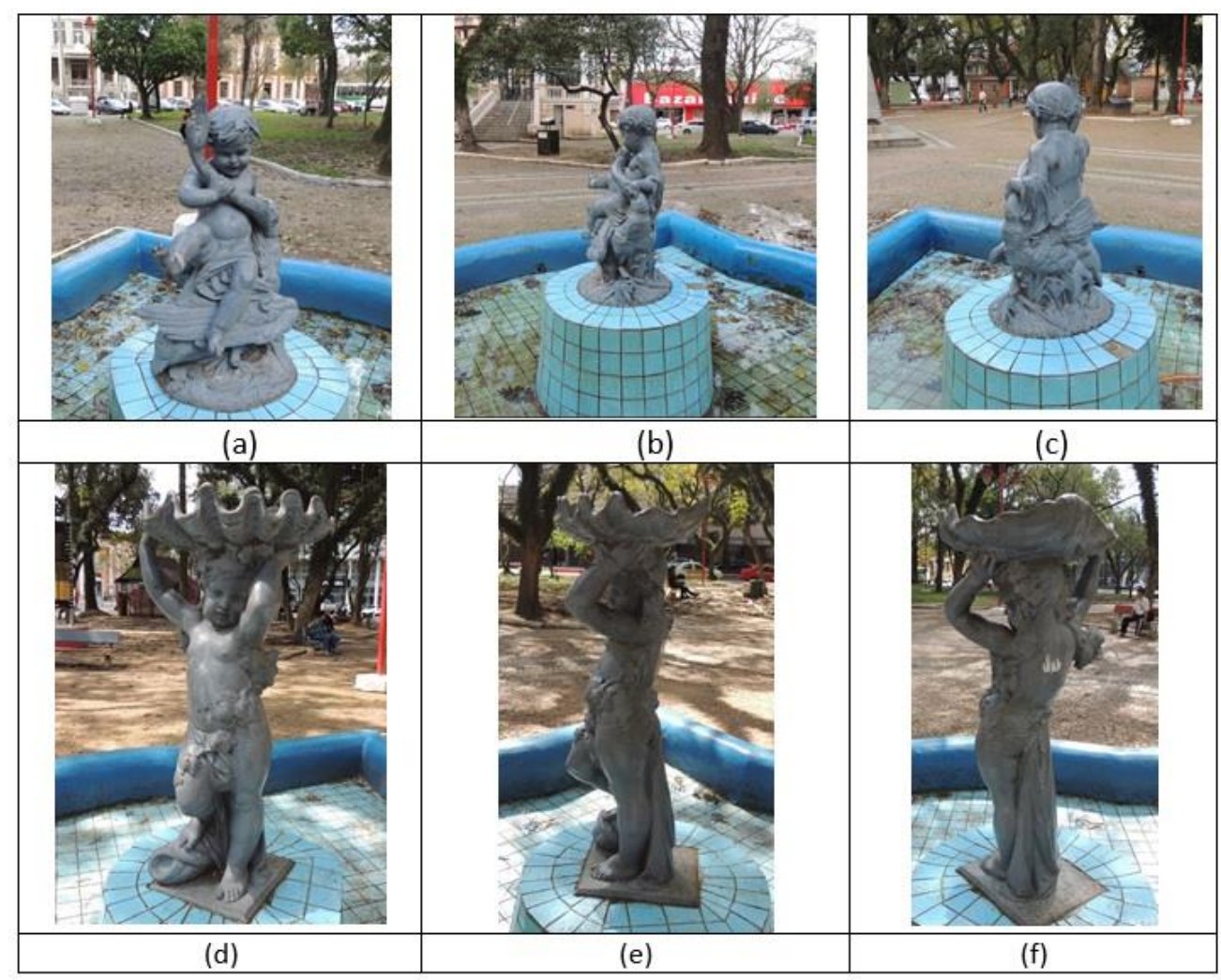

Fonte: autores 2019. 
A Figura $2(a, b)$ marca uma síntese do que foi realizado na Fotogrametria. Nessa fase, as imagens obtidas na etapa anterior em formato "JPG" foram encaminhadas para o software da Autodesk RECAP, cuja versão educacional se encontra hospedada no computador de IP 192.168.8.112. O processamento das imagens por fotogrametria ocorre da seguinte forma: inicialmente seleciona-se a opção no RECAP: "escolha da forma de adição das imagens JPG", a Figura 2 (a) mostra a imagem com a opção "carregamento das fotos", nessa opção foram adicionadas 46 fotos do Anjo 1 e para a Figura 2(b) foram inseridas 41 fotos do Anjo 2, respectivamente. Na sequência, foi necessário selecionar a opção "criação de um novo projeto de modelagem", que caracteriza o momento em que foi feito o upload do projeto para a nuvem pessoal. As próximas etapas são referentes ao download do modelo e tela do RECAPPHOTO, de acordo com Figura 2 (c, d, e, f) dos modelos.

Figura 2 - Mostra as imagens dos anjos sendo selecionadas e carregadas no programa $\operatorname{RECAP}(a, b)$ e tela do RECAPPHOTO (c, d, e,f).

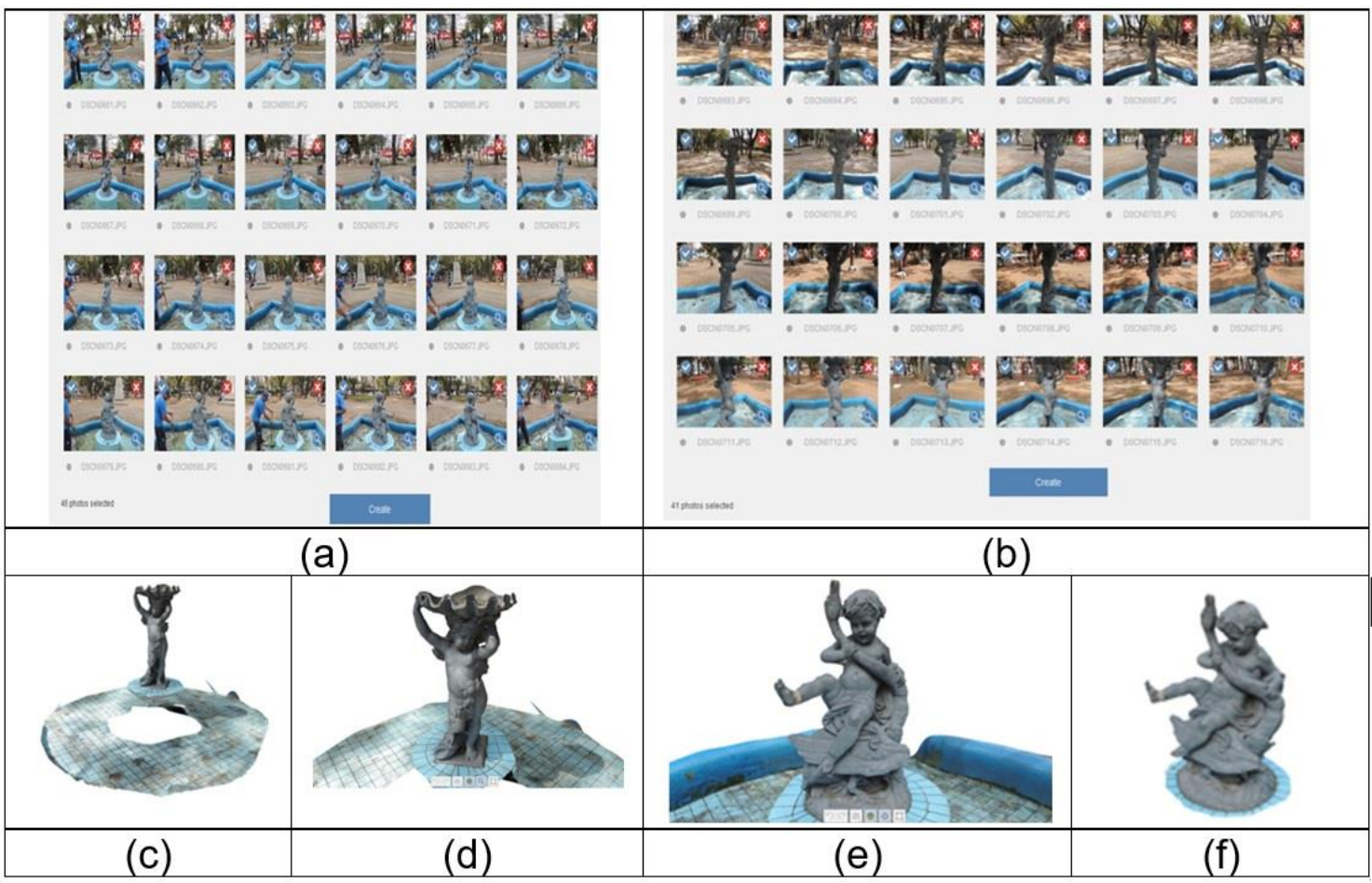

Fonte: autores 2019. 


\subsection{PROTOTIPAGEM}

Para Cóser (2010), o termo CAM (Computer Aided Machining ou Computer Aided Manufacturing) refere-se a todo processo de fabricação controlado pelo computador. Suas origens remontam à década de 1940, com o desenvolvimento das máquinas de usinagem CN (Numeric Control), que posteriormente evoluíram para máquinas CNC (Computer Numeric Control) devido às vantagens da automação do uso computacional no processo de fabricação da peça final. A tecnologia integrada dos dois sistemas gera o par CAD /CAM, no qual podemos gerar uma peça virtual (vista na tela do computador) e obter sua saída física automatizada por uma integração com o software e a máquina de fabricação. Sistemas CAD/CAM têm por característica centralizar várias etapas do processo produtivo em um eixo central, ou uma base de dados, como famílias de peças ou análises estruturais de materiais utilizados.

A tecnologia de impressão 3D utilizada nesse trabalho foi a FDM, que constrói o modelo por extrusão de filamentos de polímeros, aquecidos num cabeçote com movimentação nas coordenadas x e y, além de uma plataforma movimentando-se no sentido vertical do eixo $z$. Além disso, possuem um cabeçote onde o fio do material termoplástico é direcionado por guias rotativas, para atravessar o bico extrusor aquecido, construindo, por sua vez, camada a camada o modelo e os suportes de sustentação.

A Figura 3 (a) mostra o momento em que a peça está sendo carregada no software REPETIER HOST. Nesse sentido, foi necessário clicar no ícone "carregar" e procurar o arquivo do tipo STL da respectiva peça que irá abrir na tela. A imagem da Figura 3 (b) mostra a projeção 3D da peça no programa, no entanto é necessário clicar em um ícone localizado no canto superior direito para ajustar a escala da altura, largura e profundidade, sendo que, nesse ícone, diminuiu-se 95 vezes o objeto em relação ao tamanho original que foi gerado pelo RECAP. Na Figura 3 (c) foi realizado o fatiamento, que significa a preparação da peça para a impressão pelo dispositivo CURAENGINE, com configuração de $0,15 \mathrm{~mm}$ de preenchimento, polímero ABS de coloração laranja e com material suporte tocando a base. Em relação ao Anjo 1, nota-se que o tempo de impressão da peça foi de 3 horas, 18 minutos e 42 segundos, com um total de 502 camadas. Já para a Figura 3 (d), Anjo 2, o tempo de impressão foi de 22 horas, 26 minutos e 29 segundos, com um total de 1313 camadas. Vale ressaltar que a diferença de horas de impressão entre os anjos ocorreu porque no Anjo 2 foi utilizado mais material de suporte. 
Figura 3 - Detalhamento da configuração de impressão Anjo 1 e 2.

\begin{tabular}{|c|c|c|}
\hline Dados & Anjo 1 & \\
\hline PDojeção na impressora & & \\
& & \\
& & \\
& & \\
& & \\
\hline Escala de impressão & & \\
\hline Qualidade impressão & $1.9 \mathrm{~mm}$ & 0.95 \\
\hline Tipo de suporte & Tocando a base & Tocando a base \\
\hline Contagem de camadas & 502 & 1313 \\
\hline Linhas totais & 388026 & 1887723 \\
\hline Filamento necessário & $5800 \mathrm{~mm}$ & $43025 \mathrm{~mm}$ \\
\hline Tempo estimado & $3 \mathrm{~h}: 18 \mathrm{~min}: 42 \mathrm{~s}$ & $22 \mathrm{~h}: 26 \mathrm{~min}: 29 \mathrm{~s}$ \\
\hline \multicolumn{2}{|c|}{} \\
\hline
\end{tabular}

Fonte: autores 2020

\section{RESULTADO E DISCUSSÃO}

A Figura $4(a, b, c)$ a seguir mostra o Anjo 1 durante o processo de fabricação e já impresso. A Figura 4 (d, e) mostra os processos análogos, mas para o Anjo 2.

Figura 4 - Imagens dos objetos sendo impressos (a,b,d) e finalizados Anjo 1 e 2 (c,e).

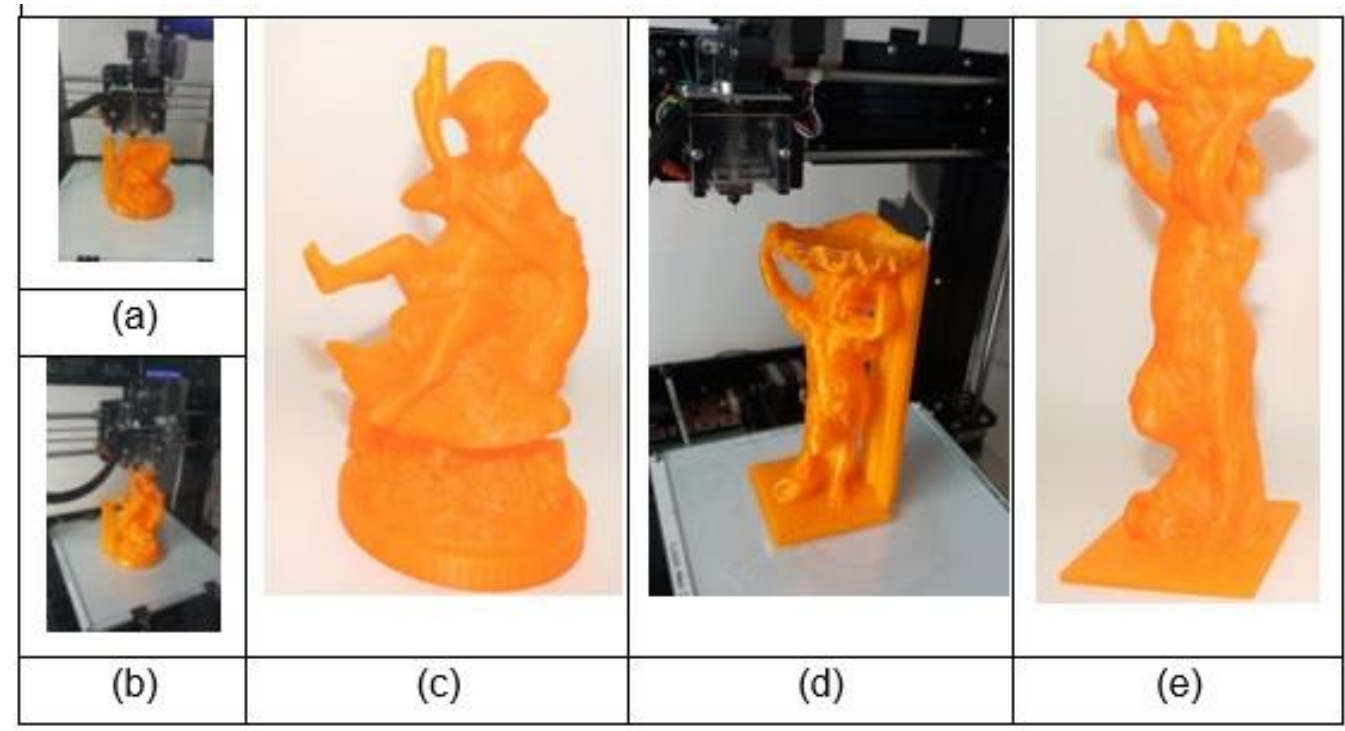

Fonte: autores 2020 
Ao final dessa atividade, a equipe envolvida pôde refletir sobre o impacto que essa ação irá causar para a comunidade acadêmica e sociedade, ou seja, percebeu-se que será possível modelar outras estatuetas e bustos de outras obras que estão espalhadas nas praças e locais públicos da cidade e/ou região e que correm os mesmos riscos das atuais. Essa ação vai ao encontro dos trabalhos de Veiga et al. (2013), Tranjan; Ferreira; Lucas (2019), Lu, Chenling (2020) e, mais recentemente, de Bonora et al. (2021), que reproduziram estátuas e ao final concluíram que as réplicas ficaram muito semelhante ao modelo original.

Em relação à modelagem 3D realizada por fotogrametria constatou-se que ela foi muito satisfatória, visto que as estatuetas estavam dispostas em locais abertos, o que inviabilizariam o uso de outras técnicas de modelagem, como o uso do scanner 3D. A fotogrametria também foi utilizada por Matos (2020) que, de forma análoga, detectou que em locais com intensidade de luz e brilho os scanners modificavam a imagem gerada e, por isso, ele optou por recorrer à técnica da fotogrametria. Roussel et al. (2019) acrescenta, no tocante, à fotogrametria, que é necessário normalizar a linguagem de comunicação, a fim de evitar mal entendidos entre os profissionais que se interessam pela recuperação e manutenção de obras de arte.

Também foi sugerido, ao final do trabalho pelos participantes, que as imagens digitalizadas façam parte de um acervo digital ou de uma plataforma virtual que poderá ser acessada para fins acadêmicos e de pesquisa por estudantes, professores, historiadores, pesquisadores e todos que se preocupam com os bens patrimoniais.

Trabalhos com o de Donadio et al. (2018) também destacam e enfatizam sobre essas possibilidades e sinalizam que muitos museus se apropriam dessas tecnologias com intuito de fazerem exposições virtuais. Da mesma forma, essa manifestação do grupo de participantes abre possibilidades que vão ao encontro do que dizem Freitas et. al. (2020), que a documentação gerada permite a obtenção do registro digital de obras para a pesquisa e preservação.

Outro fato relatado é que o grupo deveria doar as réplicas desses e outros protótipos para o núcleo de apoio aos deficientes visuais da Universidade Federal do Pampa, para que eles pudessem estudar e analisar a forma dessas esculturas através do contato, pois os objetos já estão em escala reduzida. 
Em síntese, detectou-se através dessa iniciativa, que é possível, de forma rápida e econômica e, com o uso da tecnologia, desenvolver projetos, pesquisas em prol da conservação do patrimônio.

Isto vai ao encontro das constatações de outros autores como Dezen-Kempter et al. (2015), Padín Devesa; Buchón Moragues; Sánchez Jiméne (2015), que alertam sobre o crescimento de novas ferramentas tecnológicas em prol da conservação patrimonial. Assim como Cóser (2010) e Veiga et al. (2013), os quais enfatizam que a tecnologia permite que se exerçam funções complexas de maneira muito rápida.

Da mesma forma, acredita-se estar indo ao encontro das observações de Castro (2019), que relatam sobre a importância de se ter mais ações no sentido de preservar e promover a valorização desses bens, mesmo que de forma acadêmica, como no presente estudo.

\section{CONSIDERAÇÕES FINAIS}

Através desta investigação, pode-se perceber que a conservação e restauração é uma área que está em constante evolução e que tem por objetivo garantir a preservação da memória social, que visa ao aumento da vida útil do objeto.

Fica a ressalva de que esta pesquisa também possui a finalidade de refletir sobre a problemática exposta, de conservar esses bens patrimoniais na cidade, com foco também de despertar o interesse de outros pesquisadores para que o tema seja mais explorado no contexto da nossa região.

As tecnologias utilizadas por meio da modelagem (fotogrametria) e prototipagem (impressora 3D), de forma geral, oferecem inúmeras vantagens e que poderão ser avaliadas no futuro, como a análise dos estágios de conservação e físico desses monumentos. Apesar de ser uma tecnologia inovadora, os acessos aos recursos são considerados dos mais viáveis para quem se interessa por este tipo de investigação.

Vale lembrar que, a partir dessa experiência, será possível construir um banco de dados com modelos diversos. Os modelos projetados em 3D podem ser também modelados em ambiente de realidade virtual, o que permite ampliar o acesso de mais pessoas em prol de reforçar o conhecimento da história. 
Pretende-se, com esta pesquisa, dar continuidade ao trabalho, selecionando outras peças para realizar a fotogrametria e posterior impressão 3D por prototipagem rápida, perpetuando um acervo com obras de valor inestimável para a preservação da história das artes na cidade de Bagé, região e do Brasil.

\section{REFERÊNCIAS}

BONFADA, C. de F.; KAUFFMANN, A. R.; SILVA, F. P. da. Desenvolvimento e avaliação de réplicas em resinas de bens do patrimônio cultural com uso de digitalização 3D e fabricação digital. Gestão \& Tecnologia de Projetos, São Paulo, v. 15, n. 1, p. 42-53, 2020. DOI:

https://doi.org/10.11606/gtp.v15i1.152672

BONORA, V. et al. Photogrammetry and 3D Printing for Marble Statues Replicas: Critical Issues and Assessment. Sustainability, Switzerland, v. 13, n. 2, 680, 2021. DOI:

https://doi.org/10.3390/su13020680

BOTELHO, D. M. Nos telhados de Pelotas/RS: revelando rasgos no espaço urbano através de fotografias e cartões postais. 2013. Tese (Doutorado em Geografia) - Universidade Federal do Rio Grande do Sul, Porto Alegre, 2013. Disponível em: http://hdl.handle.net/10183/85040 .Acesso em: 21 abr. 2020.

CASTRO, T. M. M. de. Esculturas urbanas metálicas do final do século XIX e início do XX histórico e valores. In: SEMINÁRIO BRASILEIRO DE MUSEOLOGIA, 4., 2019, Brasília. Anais eletrônicos [...]. Brasília: Universidade de Brasília, 2019. p. 28. Caderno de Resumos. Disponível em: http://www.sebramusrepositorio.unb.br/index.php/4sebramus/4sebramus/paper/view/161. Acesso em: 21 abr. 2020.

CÓSER, T. J. Possibilidades da produção artística via prototipagem rápida= processos CAD/CAM na elaboração e confecção de obras de arte e o vislumbre de um percurso poético individualizado neste ensaio. 2010. Dissertação ( Mestrado em Artes) - Universidade Estadual de Campinas, Campinas, 2010. Disponível em: http://repositorio.unicamp.br/jspui/handle/REPOSIP/283927. Acesso em: 21 abr. 2020

De la Torre-Cantero, J. et al. Creación de réplicas de patrimonio escultórico mediante reconstrucción 3D e impresoras 3D de bajo coste para uso en entornos educativos. Arte, individuo y Sociedad, Madrid, v. 27, n. 3, p. 429-446, 2015. DOI: https://doi.org/10.5209/rev_ARIS.2015.v27.n3.45864

Dezen-Kempter, E. et al. Escaneamento 3D a laser, fotogrametria e modelagem da informação da construção para gestão e operação de edificações históricas. Gestão \& Tecnologia de Projetos, São Paulo, v. 10, n. 2, p. 113-124, 2015. DOI: https://doi.org/10.11606/gtp.v10i2.102710 
DONADIO, E. et al. Three-Dimensional (3D) modelling and optimization for multipurpose analysis and representation of ancient statues. In: GONZALEZ-AGUILERA, D. (ed.). Latest Developments in Reality-Based 3D Surveying and Modelling. Switzerland: MDPI Books, 2018. p. 95-118. E-book. DOI: https://doi.org/10.3390/books978-3-03842-685-1-5

FERNANDEZ CÓRDOBA P. A. Levantamento fotogramétrico de monumentos arquitetônicos para projetos de restauração: estudo de caso: Palácio Itamaraty. 2012. Dissertação (Mestrado em Estruturas e Construção Civil) - Universidade de Brasília, Brasília, 2012. Disponível em: https://repositorio.unb.br/handle/10482/12656. Acesso em: 21 abr. 2020.

GINÉ, A. B. Fotogrametria per a la conservació-restauració de béns culturals. UNICUM, Barcelona, $n$. 17, p. 57-76, 2018. Disponível em: https://raco.cat/index.php/UNICUM/article/view/353665. Acesso em: 21 jul. 2020.

LU, C. Digital Restoration Proposal for Notre Dame statues. 2020. Dissertação (Master of Science Interactive Digital Media) - University of Dublin, Irlanda, 2020. Disponível em: https://www.scss.tcd.ie/publications/theses/diss/2020/TCD-SCSS-DISSERTATION-2020-008.pdf. Acesso em: 21 mar. 2020.

MATOS, M. J. S. de. Restauro da escultura" Sacrifício de Isaac" de Simon Troger com recurso a técnicas digitais 3D: o papel do escultor na reconstrução volumétrica numa intervenção de conservação e restauro. 2020. Dissertação (Mestrado em Ciências da Conservação, Restauro e Produção de Arte Contemporânea) - Universidade de Lisboa, Faculdade de Belas Artes, Lisboa, 2020. Disponível em: https://repositorio.ul.pt/handle/10451/44671. Acesso em: 20 mar. 2020.

MORAGI, J. de B. Espaços públicos e territorialidades: um estudo de caso da praça Silveira Martins em Bagé- Rio Grande do Sul. Formação (Online), São Paulo, v. 27, n. 50, 2020. DOI: https://doi.org/10.33081/formacao.v27i50.6327

PADÍN DEVESA, J; BUCHÓN MORAGUES, F. F.; SÁNCHEZ JIMÉNE, D. Fotogrametria de objeto cercano para la rehabilitación ornamental de edificios. In: CONGRESO INTERNACIONAL ARTE CIENCIA CIUDAD, 2., Valência,2015. Actas[...]. Valência :Editorial Universitat Politècnica de València, 2015. p. 112-117. Disponível em:

http://ocs.editorial.upv.es/index.php/ASC/ASC15/paper/viewFile/2027/1198. Acesso em: 21 mar. 2020.

PRAÇA Silveira Martins. Blog Bagé, terra do tempo e o vento, Bagé, 26 jan. 2011a. Disponível em: http://cidadebage.blogspot.com/2011/01/praca-silveira-martins.html.Acesso em: 22 jul. 2020.

PRAÇA Silveira Martins. Blog Bagé, terra do tempo e o vento, Bagé, 13 mar. 2011b. Disponível em: http://cidadebage.blogspot.com/2011/03/chafariz-praca-silveira-martins.html. Acesso em: 22 jun. 2020. 
ROUSSEL, R. et al. (2019). A digital diagnosis for the "Autumn" statue (Marseille, France): Photgrammetry, digital cartography and construction of a Thesaurus. International Archives of the Photogrammetry, Remote Sensing \& Spatial Information Sciences, Spain, v. 42-2/W15, p. 10391046, 2019. DOI: https://doi.org/10.5194/isprs-archives-XLII-2-W15-1039-2019

RUTH, N. A. A Praça Marechal Floriano Peixoto: espaço de construção e preservação da memória da cidade de Ponta Grossa. 2020. Dissertação (Mestrado em Ensino de História) - Universidade Estadual de Ponta Grossa, Ponta Grossa, 2020. Disponível em:

https://tede2.uepg.br/jspui/handle/prefix/3183. Acesso em: 20 maio. 2020.

SÁ, A. M. e et al. Repositório 3D de obras de arte nos espaços públicos do Rio de Janeiro. In: SEMINÁRIO TECNOLOGIA E CULTURA:DISSEMINAÇÃO DO PATRIMÔNIO POR MEIO DA TECNOLOGIA, 4., Rio de Janeiro, 2019. Apresentações [...]. Rio de Janeiro : Fundação Casa de Rui Barbosa, 2019. Disponível em:

http://rubi.casaruibarbosa.gov.br/jspui/handle/20.500.11997/11926. Acesso em: 20 mar. 2020

SELDEN, R. Z.; DOCKALL, J. E.; SHAFER, H. J. Lithic morphological organisation: Gahagan bifaces from the Southern Caddo Area, Digital Applications in Archaeology and Cultural Heritage, Italy, v. 10, sep. 2018. DOI: DOI: https://doi.org/10.1016/j.daach.2018.e00080

SILVA, T. G. P. Um toque no sagrado: relação simbólica entre devotos e esculturas policromadas sob o olhar da conservação. 2019. Trabalho de Conclusão de Curso (Bacharelado em Conservação e Restauração) - Universidade Federal do Rio de Janeiro, Rio de Janeiro, 2019. Disponível em: https://docplayer.com.br/191036258-Um-toque-no-sagrado-relacao-simbolica-entre-devotos-eesculturas-policromadas-sob-o-olhar-da-conservacao.html. Acesso em 20 mar. 2020.

TOMMASELLI, A. M. G. et al. Fotogrametria: aplicações a curta distância. In: MENEGUETE JÚNIOR, M.; ALVES, N. (ed.). FCT 40 anos: perfil científico - educacional. São Paulo :UNESP, 1999. p. 147159.Disponível em:

https://www.researchgate.net/publication/267035028_FOTOGRAMETRIA_aplicacoes_a_curta_dist ancia\#read. Acesso em: 21 mar. 2020.

TRANJAN, C. G.; FERREIRA, C. C.; LUCAS F. C. R. Réplica de objetos de arte por meio de fotogrametria e prototipagem rápida In: INTERNATIONAL CONFERENCE ON GRAPHICS ENGINEERING FOR ARTS AND DESIGN, 13., 2019, Rio de Janeiro. Anais eletrônicos [...]. Rio de Janeiro : ABEG, 2019. P. 994-1003. Disponível em:

http://www.graphica2019.org/assets/doc/Anais_Graphica_2019.pdf. Acesso em: 20 Mar. 2020.

VEIGA, M. et al. Impressão 3D de um elemento complexo da Arquitetura de pelotas: Relato de experiência. In: CONGRESSO DE INICIAÇÃO CIENTÍFICA DA UNIVERSIDADE FEDERAL DE PELOTAS, 22., 2013, Pelotas. Anais eletrônicos [...]. Pelotas : UFPEL , 2013. Disponível em: http://cti.ufpel.edu.br/cic/arquivos/2013/SA_03180.pdf. Acesso em: 20 mar. 2020. 